\title{
RESEARCH
}

Open Access

\section{Left-side vs. right-side hepatectomy for hilar cholangiocarcinoma: a meta-analysis}

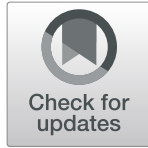

Wenxuan Wu ${ }^{1,2}$, Qiyang Cheng ${ }^{1,2}$, Junru Chen ${ }^{1,2}$, Diyu Chen ${ }^{1,2}$, Xiaode Feng ${ }^{1,2}$ and Jian $\mathrm{Wu}^{1,2,3^{*}}$

\begin{abstract}
Goals: We aim to draw a conclusion which type of hepatectomy could be the priority for hilar cholangiocarcinoma patients.

Background: Surgery is established as only potentially curative treatment for hilar cholangiocarcinoma. However, whether hepatectomy should be preferred to the left-side hepatectomy, which includes left hemihepatectomy, extended left hemihepatectomy, and left trisectionectomy, or right-side hepatectomy, which represents right hemihepatectomy, extended right hemihepatectomy, and right trisectionectomy, is debated. In this meta-analysis, we evaluated and compared the efficacy and safety of left-side hepatectomy and right-side hepatectomy in patients with hilar cholangiocarcinoma.
\end{abstract}

Study: We systematically retrieved the MEDLINE, PubMed, and Cochrane library and related bibliography up to February 2020. The primary outcome is overall survival, and the secondary outcome includes 1-, 3-, and 5-year survival rates, morbidity, mortality, R0 resection rate, and operation time. Based on heterogeneity, fixed-effects model or random-effects models were established through meta-analysis.

Results: Eleven studies (11 cohort studies, totally 1031 patients) were involved in this study. The overall survival of patients who underwent left-side hepatectomy was comparable to that of patients who underwent right-side hepatectomy (hazard ratio, 1.27 [95\% confidence interval, 0.98-1.63]). And there was no significant difference observed in 1-year (relative risk, 1.01 [95\% Cl, 0.89-1.15]), 3-year (relative risk, 0.94 [95\% confidence interval, 0.80$1.11]$ ), and 5 -year survival (relative risk, 0.82 [95\% confidence interval, $0.67-1.01]$ ) rates between the left-side hepatectomy group and the right-side hepatectomy group. Comparing with the right-side hepatectomy cluster, the hilar cholangiocarcinoma patients in the left-side hepatectomy cluster presented better overall postoperative morbidity (relative risk, 0.82 [95\% confidence interval, 0.71-0.96]) and major postoperative morbidity (relative risk, 0.73 [95\% confidence interval, 0.56-0.95]). The post-hepatectomy liver failure rate (relative risk, 0.22 [95\% confidence interval, 0.09-0.56]) and procedure-related mortality (relative risk, 0.41 [95\% confidence interval, 0.23-0.70]) in the left-side hepatectomy group were better than those of the right-side hepatectomy group. Besides, the R0 resection rate was similar between the left-side hepatectomy group and the right-side hepatectomy group (relative risk, 0.95

\footnotetext{
* Correspondence: drwujian@zju.edu.cn

'Division of Hepatobiliary and Pancreatic Surgery, Department of Surgery, First Affiliated Hospital, Zhejiang University School of Medicine, Hangzhou 310003, Zhejiang Province, China

${ }^{2}$ Key Laboratory of Combined Multi-organ Transplantation, Ministry of Public Health, First Affiliated Hospital, Zhejiang University School of Medicine, Hangzhou 310003, China

Full list of author information is available at the end of the article
}

C C The Author(s). 2021 Open Access This article is licensed under a Creative Commons Attribution 4.0 International License, which permits use, sharing, adaptation, distribution and reproduction in any medium or format, as long as you give appropriate credit to the original author(s) and the source, provide a link to the Creative Commons licence, and indicate if changes were made. The images or other third party material in this article are included in the article's Creative Commons licence, unless indicated otherwise in a credit line to the material. If material is not included in the article's Creative Commons licence and your intended use is not permitted by statutory regulation or exceeds the permitted use, you will need to obtain permission directly from the copyright holder. To view a copy of this licence, visit http://creativecommons.org/licenses/by/4.0/ The Creative Commons Public Domain Dedication waiver (http://creativecommons.org/publicdomain/zero/1.0/) applies to the data made available in this article, unless otherwise stated in a credit line to the data. 


\begin{abstract}
(Continued from previous page)
[95\% confidence interval, 0.87-1.03]). And the operation time for the left-side hepatectomy was significantly longer than that for the right-side hepatectomy (mean difference, 38.68 [95\% confidence interval, 7.41-69.95]).

Conclusion: Through meta-analysis, we explored the comparable long-term outcomes and better short-term outcomes in the left-side hepatectomy group as is compared to the right-side hepatectomy group of hilar cholangiocarcinoma patients. In this study, the evidence obtained might indicate that the choice of left-side hepatectomy or right-side hepatectomy depends on the site of hilar cholangiocarcinoma in every patient.
\end{abstract}

Keywords: Hilar cholangiocarcinoma, Perihilar cholangiocarcinoma, Left-side hepatectomy, Right-side hepatectomy, Meta-analysis

\section{Introduction}

Hilar cholangiocarcinoma (HCCA), a type of cholangiocarcinoma, is classified based on the anatomical location and is located in the area between the second-degree bile ducts and the insertion of the cystic duct into the common bile duct [1]. The prognosis of HCCA patients is poor. Radical surgery with negative margins (R0) is the only potentially curative treatment for this disease. However, frequent metastasis and recurrence remain the major obstacles for the prognosis of HCCA patients who underwent surgical resection (a 1-year survival rate of $80 \%$ and a 5 -year survival rate of $39 \%$ ) [2, 3]. Recently, it is considered to be the standard surgical procedure of HCCA, which includes bile duct resection combined with major hepatectomy, caudate lobe resection, lymph node dissection, and vascular resection when necessary, resulting in improved R0 resection rate and long-term survival [4-8].

Up to now, right-side hepatectomy $(\mathrm{RH})$ is recognized as an accepted option for major liver resection in HCCA treatment $[9,10]$. Tumor location is a major factor in operation methods selection for HCCA, and the following factors also should be considered: (1) Length of hepatic duct: the extrahepatic portion of left hepatic duct is longer than the right one. (2) Oncological characteristic: due to the vertical spread characteristic of HCCA, the right hepatic artery is susceptible to be invaded. Moreover, the right hepatic artery usually travels behind the proximal bile duct near the hepatic hilum, making $\mathrm{RH}$ more advantageous in terms of radicality. (3) The anatomical structure on the right side of the hepatic hilum is complicated, with many anatomical variations; (4) it is easier to complete caudate lobectomy [10-13]. However, $\mathrm{RH}$ is confirmed to be the risk of future liver remnant (FLR) deficiency and even postoperative liver failure (PHLF). Although preoperative biliary drainage and portal vein embolization (PVE) were utilized into the HCCA preoperative management, it is still unclear whether these measurements could improve in postoperative morbidity and mortality $[14,15]$.

Whereas left-side hepatectomy $(\mathrm{LH})$ is more complicated and sometimes arterial reconstruction is needed during the operation [16], it is still an essential option for the HCCA located in the left liver [17, 18]. Generally, because of the anatomical structure, the patients who underwent LH possess more FLR volume, which means it could take patients from less PHLF risk.

Many studies reported that RH can achieve better long-term survival resulted from higher R0 resection rate [13, 16]. Nevertheless, Govil et al.'s [19] research reveals that $\mathrm{LH}$ is comparable to $\mathrm{RH}$ in long-term survival. Due to the rarity of HCCA and the small number of cases, the comparison between the effects of $\mathrm{LH}$ and $\mathrm{RH}$ remains unknown.

The aim of this meta-analysis is to conduct a statistical evaluation based on the existing studies, to clarify the long-term outcome of the $\mathrm{LH}$ and $\mathrm{RH}$ of HCCA, and to compare the differences of short-term outcome, R0 resection rate, and operation time, in order to provide evidence for clinical application.

\section{Materials and methods}

\section{Search strategy}

This meta-analysis followed the Preferred Reporting Items for Systematic Review and Meta-Analyses (PRIS MA) statement [20] and the Meta-analysis of Observational Studies in Epidemiology (MOOSE) guidelines [21]. A comprehensive systematic search was performed on PubMed, EMBASE, and Cochrane Library through to February 3, 2020. The search strategy was to combine keywords including "hilar cholangiocarcinoma," "Klatskin tumor," "left-side hepatectomy," and "right-side hepatectomy" into various combinations. To identify more relevant literature, a manual search was performed on references of all included literature. Restrictions were not placed on any point of the search. In addition, the search process was completed independently by two authors (Wenxuan $\mathrm{Wu}$ and Qiyang Cheng), and the disagreement reached consensus through discussion. Our protocol was registered on the International Platform of Registered Systematic Review and Meta-Analysis Protocols INPLASY (https://inplasy.com/), and the registration number is INPLASY202130004. Moreover, our 
protocol is available with the DOI number (10.37766/ inplasy2021.3.0004).

\section{Inclusion criteria and exclusion criteria}

Two authors (Wenxuan Wu and Qiyang Cheng) independently screened the titles and abstracts of all literatures and reviewed further full texts if appropriate. Literature that reported the outcomes of left-side hepatectomy versus right-side hepatectomy in patients with HCCA and met the following criteria were included: (i) randomized controlled trials (RCTs), cohort studies, or case-control studies; (ii) adult patients with HCCA; (iii) language-free publication comparing left-side hepatectomy and right-side hepatectomy for HCCA; and (iv) include at least one of the following endpoints: overall survival (OS), 1-year survival rate, 3-year survival rate, 5year survival rate, operating time, R0 resection rate, postoperative morbidity, PHLF, procedure-related mortality. Exclusion criteria include the following: (i) study design type without explicit accountability; (ii) patients with intrahepatic cholangiocarcinoma, distal cholangiocarcinoma, and gallbladder carcinoma; (iii) no controls; (iv) duplicates; (v) unable to extract valid outcome data from the literature; and (vi) conference, editorials, reviews, case reports, commentaries, letters, research involving animal experiments, cohorts with fewer than 10 cases, and when full text was not available.

\section{Data abstraction and quality assessment}

For each literature included, data were extracted independently by two authors (Wenxuan $\mathrm{Wu}$ and Junru Chen) using a pre-made spreadsheet. The data to be extracted include (i) general information: first author, year of publication, and country; (ii) study characteristics: study design, study period, sample size, and duration of follow-up; (iii) patient and preoperative characteristics: gender, age, Bismuth classification, proportion of biliary drainage including percutaneous biliary drainage (PBD) and endoscopic biliary drainage (EBD) before surgery, and proportion of portal vein embolization (PVE); (iv) operative data: type of resection, operation time, R0 resection rate, and proportion of caudate lobectomy; (5) postoperative data: overall survival (OS), 1-year survival rate, 3-year survival rate, 5-year survival rate, postoperative morbidity, PHLF, and procedure-related mortality.

The primary endpoint of analysis was OS. OS was calculated from the time of surgery to the death or last contact. Postoperative morbidity includes overall morbidity and major morbidity (according to Clavien-Dindo classification, Dindo grades III-V). Procedure-related mortality was considered to include operative mortality, postoperative mortality, in-hospital mortality, and 90day mortality. Hazard ratio (HR) is most appropriate for analyzing time-to-event outcomes. Given that only two literatures reported the values directly, this meta-analysis used the method of Parmar et al. [22] to extract data from the Kaplan-Meier curve and then used the Excel sheet published by Tierney et al. [23] to calculate HR.

Similarly, two authors (Wenxuan Wu and Junru Chen) independently assessed the quality of each literature. The Newcastle-Ottawa Quality Assessment Scale (NOS) [24] was used to assess quality of the cohort study. This tool includes three categories of selection, comparability, and outcome, with a maximum score of 9 stars and more than 6 stars are considered as high quality.

\section{Statistical analysis}

To compare OS, we used HR and its $95 \%$ confidence interval (CI), and the other dichotomous data were calculated using relative risk (RR) and its 95\% CI. Continuous data were presented as mean difference (MD) with 95\% CI. Some literatures used the median and range to describe continuous data. In order to calculate uniformly, we used the formulas and tables provided by Luo et al. [25] and Wan et al. [26] to convert the data into mean and standard deviation (SD). Heterogeneity among the included studies was assessed using the $Q$ test, and $P<0.1$ was considered heterogeneous. The value of $I^{2}$ is used to quantify the degree of heterogeneity, specifically, when the $I^{2}$ values were $25 \%, 50 \%$, and $75 \%$, the corresponding heterogeneity is low, medium, and high [27]. Fixed-effects model was selected when there is no heterogeneity; otherwise, random-effects model was considered for pool data. Subgroup analyses were performed to assess the impact of region and year of publication on surgical outcome and survival, taking into account differences in treatment and surgical outcomes between eastern and western centers, as well as the ongoing development of modern surgical techniques. The cutoff point for subgroup analysis is the mean of the year of publication. Plotting a funnel plot and visually evaluating the symmetry of the funnel plot were done to see if there were publication biases. Begg's test and Egger's test were also conducted to explore potential publication bias, with a cutoff level of $P<0.05$. Unless otherwise noted, two-sided $P$ values $<0.05$ were considered statistically significant. All statistical analyses for the meta-analysis were generated using STATA/MP software (version 14.0).

\section{Results}

\section{Literature search}

Through a comprehensive search in PubMed, EMBASE, and Cochrane Library databases, a total of 694 citations were identified. Subsequently, after excluding 198 duplicate articles, our analysis removed 155 citations including case reports, reviews, conference papers, animal experiments, and research on children (Fig. 1). Based on 


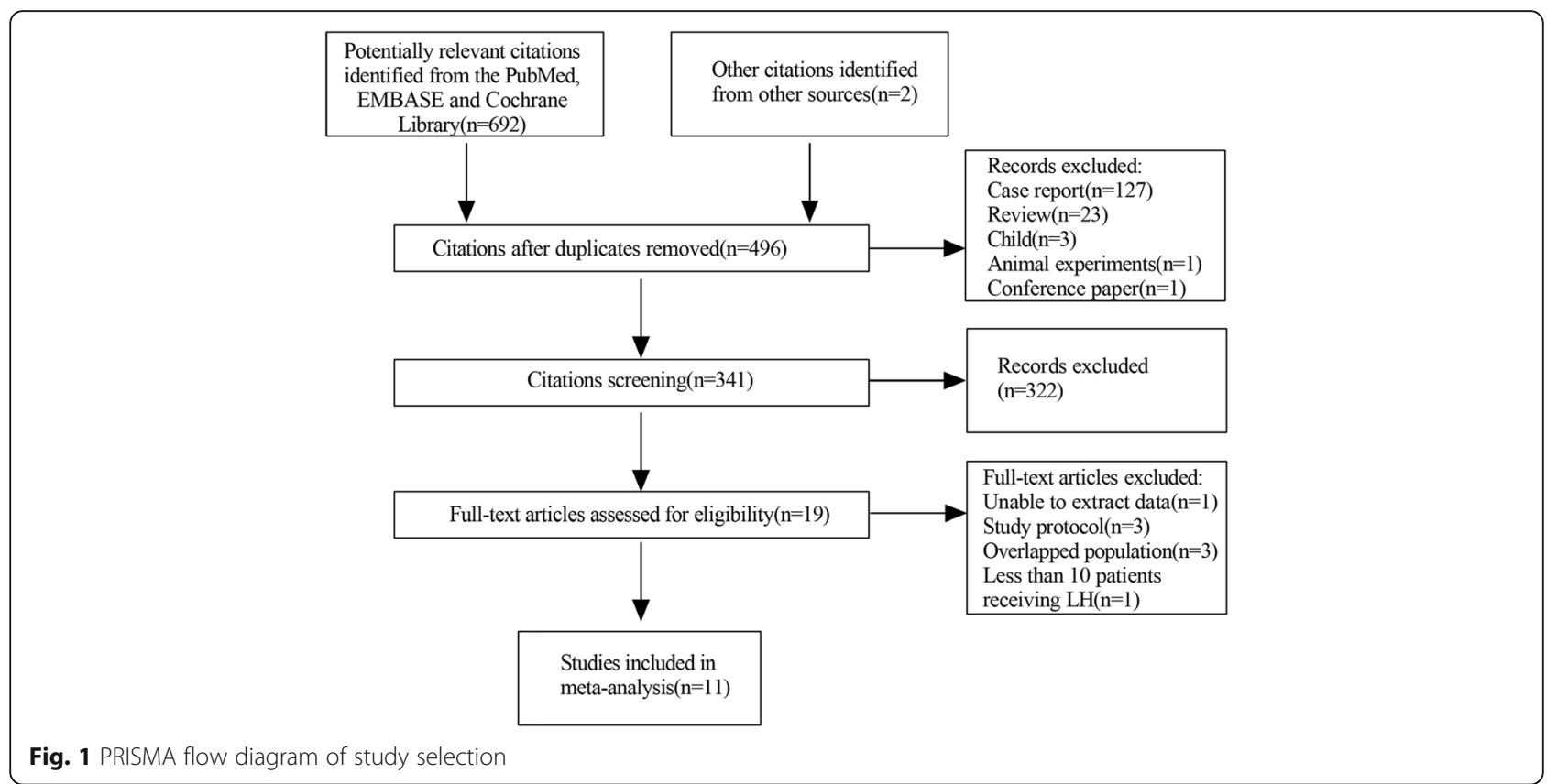

screening the title and abstract, an additional 322 citations were excluded, and finally, 19 unique citations entered the full-text review. In order to retain the most recent and complete data, three studies based on the same population were eliminated after the further discussion by the two authors (Diyu Chen and Xiaode Feng). Eventually, 11 eligible cohort studies were included in this analysis [11, 15, 19, 28-35].

\section{Characteristics of included studies and assessment of methodological quality}

The 11 eligible retrospective-prospective cohort studies were carried out between 2001 and 2020, including a total of 1031 patients. All studies were single-center studies, most of them (7/11) were performed in Asian populations (Japan, Korea, and India), and the others (4/ 11) were based on Western populations (Germany, Italy, and USA). Seven studies were published before 2014, and four after 2014. Nine cohorts involved in our study represent the usage of PVE, seven of which conducted PVE before RH, while two of which conducted it not only before $\mathrm{RH}$ but also before $\mathrm{LH}$. As for caudate lobectomy, all patients underwent caudate lobectomy in six of eleven papers, a part of patients had been performed with caudate lobectomy in four studies, and the remaining one study described unclearly about this. The specific characteristics and data of the included studies were shown in the Table 1.

After quality evaluation, the scores of our included studies ranged from 6 to 8 , based on the NewcastleOttawa Scale. As shown in the Table 2, there were 3 literatures with $<7$ points and 8 literatures with $\geq 7$ points.

\section{Primary outcomes: overall survival}

In order to evaluate the prognosis of patients under different surgeries, we analyzed the overall survival data from ten cohorts (including 859 patients) in this study, and the data were visualized by forest plots in Fig. 2 . The pooled HR estimated based on the fixed-effects model and the random-effects model was 1.27 (95\% CI, $0.98-1.63 ; P=0.066$ ), indicating that the difference between $\mathrm{LH}$ and $\mathrm{RH}$ was not statistically significant. No significant difference was observed among studies in the estimates for OS $(\mathrm{I} 2=0 \%, P$ heterogeneity $=0.840)$. Subgroup analysis showed that the analysis results did not change due to the region, year of publication, and the number of cases of left-side hepatectomy, and the differences between $\mathrm{LH}$ and $\mathrm{RH}$ remained not significant (Table 3).

\section{Secondary outcomes}

\section{1-, 3-, and 5-year survival rates}

Five studies included 1-year survival data containing 576 patients, of which $79.0 \%$ (188 of 238) were in the $\mathrm{LH}$ group and $78.7 \%$ (266 of 338) in the RH group, seven included 3-year survival data containing 662 patients, of which $46.2 \%$ (121 of 262) were in the LH group and 49.0\% (196 of 400) in the RH group; and eight included 5-year survival data containing 798 patients, of which $28.8 \%$ (95 of 330) were in the LH group and 35.5\% (166 of 468) in the RH group. The results of the pooled 1year, 3-year, and 5-year survival rates for LH vs. $\mathrm{RH}$ are 
Table 1 Characteristics of the included studies

\begin{tabular}{|c|c|c|c|c|c|c|c|c|c|c|}
\hline Study & $\begin{array}{l}\text { Study } \\
\text { design }\end{array}$ & $\begin{array}{l}\text { Location/ } \\
\text { period }\end{array}$ & $\begin{array}{l}\text { Follow- } \\
\text { up } \\
\left(\text { months }{ }^{a}\right)\end{array}$ & $\begin{array}{l}\text { No. of } \\
\text { patients } \\
\text { (male, } \\
\%)\end{array}$ & $\begin{array}{l}\text { Age, } \\
\text { (years }^{a} \text { ) }\end{array}$ & $\begin{array}{l}\text { No. } \\
\text { of } \\
\text { stage } \\
\text { I/II/ } \\
\text { III/IV }\end{array}$ & $\begin{array}{l}\text { No. of } \\
\text { biliary } \\
\text { drainage } \\
\text { (EBD/ } \\
\text { PBD) }\end{array}$ & $\begin{array}{l}\text { No. } \\
\text { of } \\
\text { PVE }\end{array}$ & $\begin{array}{l}\text { Caudate } \\
\text { lobectomy, } \\
\%\end{array}$ & Main findings \\
\hline \multirow[t]{2}{*}{$\begin{array}{l}\text { Bednarsch } \\
\text { et al. [28] }\end{array}$} & \multirow[t]{2}{*}{$\begin{array}{l}\text { Cohort } \\
\text { study }\end{array}$} & \multirow{2}{*}{$\begin{array}{l}\text { Germany/ } \\
2011- \\
2016\end{array}$} & \multirow[t]{2}{*}{$28(0-90)$} & $\begin{array}{l}\text { LH: } 36 \\
(63.9)\end{array}$ & $67 \pm 9$ & $\begin{array}{l}1 / 0 / \\
23 / 12\end{array}$ & $35(27 / 8)$ & 0 & 100 & \multirow{2}{*}{$\begin{array}{l}\text { 3- and 5-year OS rate, } \mathrm{LH}=62 \%, 30 \% \\
\text { vs. } \mathrm{RH}=51 \%, 46 \% ; \mathrm{RO}, \mathrm{LH}=69.4 \% \text { vs. } \\
\mathrm{RH}=75.6 \%\end{array}$} \\
\hline & & & & $\begin{array}{l}\text { RH: } 45 \\
(68.9)\end{array}$ & $67 \pm 11$ & $\begin{array}{l}2 / 6 / \\
23 / 14\end{array}$ & $\begin{array}{l}46(35 / \\
11)\end{array}$ & 37 & 100 & \\
\hline \multirow[t]{2}{*}{ Govil et al. [19] } & \multirow[t]{2}{*}{$\begin{array}{l}\text { Cohort } \\
\text { study }\end{array}$} & \multirow{2}{*}{$\begin{array}{l}\text { India/ } \\
2009- \\
2015\end{array}$} & \multirow[t]{2}{*}{$14(3-64)$} & $\begin{array}{l}\text { LH: } 23 \\
\text { (NR) }\end{array}$ & $\begin{array}{l}58(20- \\
74)\end{array}$ & $\begin{array}{l}0 / 0 / \\
28 / 8\end{array}$ & $8(0 / 8)$ & 0 & $N R$ & \multirow[t]{2}{*}{$\begin{array}{l}\text { 2-year OS rate, } \mathrm{LH}=39 \% \text { vs. } \mathrm{RH}= \\
44 \%, \mathrm{RO}, \mathrm{NR}\end{array}$} \\
\hline & & & & $\begin{array}{l}\text { RH: } \\
13(N R)\end{array}$ & & & $6(0 / 6)$ & 0 & $N R$ & \\
\hline \multirow[t]{2}{*}{$\begin{array}{l}\text { Hong et al. } \\
\text { [29] }\end{array}$} & \multirow[t]{2}{*}{$\begin{array}{l}\text { Cohort } \\
\text { study }\end{array}$} & \multirow{2}{*}{$\begin{array}{l}\text { Korea/ } \\
2000- \\
2018\end{array}$} & \multirow[t]{2}{*}{ NR } & $\begin{array}{l}\text { LH: } 82 \\
(68.3)\end{array}$ & $\begin{array}{l}63.46 \pm \\
10.38\end{array}$ & $\begin{array}{l}5 / 6 / \\
43 / 28\end{array}$ & 60 & 2 & 100 & \multirow{2}{*}{$\begin{array}{l}1-, 3-\text {, and } 5 \text {-year OS rate, } \mathrm{LH}=87.3 \%, \\
38.2 \%, 24.7 \% \text { vs. } \mathrm{RH}=77.2 \%, 41.4 \%, \\
26.8 \% ; \mathrm{RO}, \mathrm{LH}=75.6 \% \text { vs. } \mathrm{RH}=72.8 \%\end{array}$} \\
\hline & & & & $\begin{array}{l}\text { RH: } 114 \\
(66.7)\end{array}$ & $\begin{array}{l}63.64 \pm \\
8.72\end{array}$ & $\begin{array}{l}4 / 13 / \\
75 / 22\end{array}$ & 93 & 45 & 100 & \\
\hline \multirow[t]{2}{*}{ Jo et al. [15] } & \multirow[t]{2}{*}{$\begin{array}{l}\text { Cohort } \\
\text { study }\end{array}$} & \multirow{2}{*}{$\begin{array}{l}\text { Korea/ } \\
2010- \\
2017\end{array}$} & \multirow[t]{2}{*}{$19(1-97)$} & $\begin{array}{l}\text { LH: } 24 \\
(62.5)\end{array}$ & $\begin{array}{l}71(53- \\
83)\end{array}$ & IV: 7 & $22(14 / 8)$ & 0 & 100 & \multirow{2}{*}{$\begin{array}{l}\text { 1-, } 3-\text {, and } 5 \text {-year OS rate, } \mathrm{LH}=82.6 \% \text {, } \\
50.6 \%, 40.5 \% \text { vs. } \mathrm{RH}=69.3 \%, 48.5 \% \text {, } \\
37.7 \% \text {; RO, LH }=75 \% \text { vs. } \mathrm{RH}=75.8 \%\end{array}$} \\
\hline & & & & $\begin{array}{l}\text { RH: } 33 \\
(66.6)\end{array}$ & $\begin{array}{l}66(42- \\
79)\end{array}$ & IV: 12 & 29(20/9) & 6 & 100 & \\
\hline \multirow[t]{2}{*}{ Lee et al. [30] } & \multirow[t]{2}{*}{$\begin{array}{l}\text { Cohort } \\
\text { study }\end{array}$} & \multirow{2}{*}{$\begin{array}{l}\text { Korea/ } \\
1995- \\
2012\end{array}$} & \multirow[t]{2}{*}{$N R$} & $\begin{array}{l}\text { LH: } 35 \\
(57.1)\end{array}$ & $\begin{array}{l}61.0 \pm \\
8.1\end{array}$ & IIIb:35 & 23 & 0 & 94.3 & \multirow{2}{*}{$\begin{array}{l}1-, 3-\text {, and } 5 \text {-year OS rate, } \mathrm{LH}=80 \% \\
47 \%, 35 \% \text { vs. } \mathrm{RH}=85 \%, 47 \%, 33 \% ; \\
\mathrm{RO}, \mathrm{LH}=85.7 \% \text { vs. } \mathrm{RH}=82.5 \%\end{array}$} \\
\hline & & & & $\begin{array}{l}\text { RH: } 103 \\
(66)\end{array}$ & $\begin{array}{l}62.1 \pm \\
9.2\end{array}$ & $\begin{array}{l}\text { Illa: } \\
103\end{array}$ & 71 & 24 & 86.4 & \\
\hline \multirow[t]{2}{*}{ Otto et al. [31] } & \multirow[t]{2}{*}{$\begin{array}{l}\text { Cohort } \\
\text { study }\end{array}$} & \multirow{2}{*}{$\begin{array}{l}\text { Germany/ } \\
\text { 1998- } \\
2011\end{array}$} & \multirow[t]{2}{*}{$N R$} & $\begin{array}{l}\text { LH: } 68 \\
\text { (75) }\end{array}$ & $\begin{array}{l}64(39- \\
83)\end{array}$ & $\begin{array}{l}0 / 0 / \\
35 / 33\end{array}$ & $N R$ & 0 & 100 & \multirow{2}{*}{$\begin{array}{l}\text { 1- and } 5 \text {-year OS rate, } \mathrm{LH}=72 \%, 22 \% \\
\text { vs. } \mathrm{RH}=73 \%, 29 \% ; \mathrm{RO}, \mathrm{LH}=72.1 \% \\
\text { vs. } \mathrm{RH}=82.4 \%\end{array}$} \\
\hline & & & & $\begin{array}{l}\text { RH: } 68 \\
(66.2)\end{array}$ & $\begin{array}{l}62(44- \\
82)\end{array}$ & $\begin{array}{l}1 / 0 / \\
37 / 30\end{array}$ & NR & 4 & 100 & \\
\hline \multirow[t]{2}{*}{ Ratti et al. [32] } & \multirow[t]{2}{*}{$\begin{array}{l}\text { Cohort } \\
\text { study }\end{array}$} & $\begin{array}{l}\text { Italy/ } \\
2004-\end{array}$ & $23(3-98)$ & $\begin{array}{l}\text { LH: } 44 \\
(68.1)\end{array}$ & $\begin{array}{l}59(36- \\
79)\end{array}$ & $\begin{array}{l}1 / 17 / \\
13 / 13\end{array}$ & $23(6 / 16)^{b}$ & 0 & 97.7 & $\begin{array}{l}\text { 3- and 5-year OS rate, } \mathrm{LH}=49.5 \% \\
35.3 \% \text { vs. } \mathrm{RH}=53.2 \%, 42.8 \% ; \mathrm{RO}, \mathrm{LH}\end{array}$ \\
\hline & & & & $\begin{array}{l}\text { RH: } 61 \\
(50.8)\end{array}$ & $\begin{array}{l}62(41- \\
82)\end{array}$ & $\begin{array}{l}1 / 20 / \\
15 / 25\end{array}$ & $39(9 / 22)^{b}$ & 29 & 93.4 & \\
\hline $\begin{array}{l}\text { Shimizu et al. } \\
{[11]}\end{array}$ & $\begin{array}{l}\text { Cohort } \\
\text { study }\end{array}$ & $\begin{array}{l}\text { Japan/ } \\
\text { 1984- }\end{array}$ & $N R$ & $\begin{array}{l}\text { LH: } 88 \\
(69.3)\end{array}$ & $\begin{array}{l}67.0 \pm \\
8.9\end{array}$ & $\begin{array}{l}\text { Illb: } \\
88\end{array}$ & $N R$ & 5 & 100 & $\begin{array}{l}1-, 3-\text {, and } 5 \text {-year OS rate, NR; RO, LH } \\
=63.6 \% \text { vs. } \mathrm{RH}=69.1 \%\end{array}$ \\
\hline & & & & $\begin{array}{l}\text { RH: } 84 \\
(56)\end{array}$ & $\begin{array}{l}67.1 \pm \\
8.0\end{array}$ & $\begin{array}{l}\text { IIIa } \\
+\mathrm{V}: \\
84\end{array}$ & $N R$ & 32 & 100 & \\
\hline $\begin{array}{l}\text { Sugiura et al. } \\
\text { [33] }\end{array}$ & $\begin{array}{l}\text { Cohort } \\
\text { study }\end{array}$ & $\begin{array}{l}\text { Japan/ } \\
\text { 2002- }\end{array}$ & $N R$ & $\begin{array}{l}\text { LH: } 12 \\
(91.7)\end{array}$ & $\begin{array}{l}65(58- \\
84)\end{array}$ & $\begin{array}{l}2 / 10 / \\
0 / 0\end{array}$ & $N R$ & 0 & 100 & $\begin{array}{l}\text { 3- and } 5 \text {-year OS rate, } \mathrm{LH}=66.7 \% \\
41.7 \% \text { vs. } \mathrm{RH}=70.8 \%, 49 \% ; \mathrm{RO}, \mathrm{NR}\end{array}$ \\
\hline & & & & $\begin{array}{l}\text { RH: } 24 \\
\text { (75) }\end{array}$ & $\begin{array}{l}68(37- \\
81)\end{array}$ & $\begin{array}{l}8 / 16 / \\
0 / 0\end{array}$ & $N R$ & 24 & 100 & \\
\hline Konstadoulakis & Cohort & USA/ & $38 \pm 30.4$ & LH: 29 & $N R$ & $N R$ & $N R$ & 0 & 77.6 & 1-, 3-, and 5-year OS rate, $\mathrm{LH}=66.7 \%$, \\
\hline & & 2006 & & $\mathrm{RH}: 20$ & NR & NR & NR & 1 & & $\begin{array}{l}35.3 \%, 21 . / \% \text { Vs. RH }=85 \%, 03.2 \%, \\
50 \% ; \text { RO, NR }\end{array}$ \\
\hline $\begin{array}{l}\text { Yamanaka } \\
\text { et al. [35] }\end{array}$ & $\begin{array}{l}\text { Cohort } \\
\text { study }\end{array}$ & $\begin{array}{l}\text { Japan/ } \\
1980-\end{array}$ & NR & $\begin{array}{l}\text { LH: } 11 \\
(54.5)\end{array}$ & $60 \pm 11$ & NR & NR & NR & 100 & $\begin{array}{l}\text { OS, HR, } 0.5395 \% \mathrm{Cl}, 0.02-15.24 ; \text { RO, } \\
\text { NR }\end{array}$ \\
\hline & & & & $\begin{array}{l}\text { RH: } 14 \\
(64.3)\end{array}$ & $55 \pm 10$ & NR & NR & NR & 93 & \\
\hline
\end{tabular}

${ }^{a}$ Sign indicates median (range); otherwise, data are expressed as mean \pm SD

${ }^{\mathrm{b}}$ In addition to EBD and PBD, biliary drainage also includes EBD + PBD

Abbreviations: NR not reported in the text, $E B D$ endoscopic biliary drainage, $P B D$ percutaneous biliary drainage, $P V E$ portal venous embolization

shown in Fig. 3. Based on the random-effects model, the pooled RR for the 1-year survival rates was 1.01 (95\% CI, $0.89-1.15 ; P=0.835)$; the pooled RR for the 3- and 5year survival rates calculated using the fixed-effects model was $0.94(95 \% \mathrm{CI}, 0.80-1.11 ; P=0.49)$ and 0.82 (95\% CI, 0.67-1.01; $P=0.067$ ), respectively.

The results indicated that there was no statistically significant difference in the 1-, 3-, and 5-year survival rates 
Table 2 The quality evaluation of cohort studies

\begin{tabular}{|c|c|c|c|c|}
\hline \multirow[b]{2}{*}{ Study } & \multicolumn{4}{|c|}{ Methodological quality } \\
\hline & Selection & Comparability & Outcome & Quality score \\
\hline Bednarsch et al. [28] & $\star \star \star \star$ & $\star$ & $\star \star$ & 7 stars \\
\hline Govil et al. [19] & $\star \star \star \star$ & $\star$ & $\star$ & 6 stars \\
\hline Hong et al. [29] & $\star \star \star \star$ & $\star \star$ & $\star \star$ & 8 stars \\
\hline Jo et al. [15] & $\star \star \star \star$ & $\star \star$ & $\star \star$ & 8 stars \\
\hline Lee et al. [30] & $\star \star \star \star$ & $\star$ & $\star \star$ & 7 stars \\
\hline Otto et al. [31] & $\star \star \star \star$ & $\star$ & $\star \star$ & 7 stars \\
\hline Ratti et al. [32] & $\star \star \star \star$ & $\star$ & $\star \star$ & 7 stars \\
\hline Shimizu et al. [11] & $\star \star \star \star$ & $\star$ & $\star \star$ & 7 stars \\
\hline Sugiura et al. [33] & $\star \star \star \star$ & $\star$ & $\star$ & 6 stars \\
\hline Konstadoulakis et al. [34] & $\star \star \star$ & $\star$ & $\star \star$ & 6 stars \\
\hline Yamanaka et al. [35] & $\star \star \star \star \star$ & $\star$ & $\star \star$ & 7 stars \\
\hline
\end{tabular}

between LH and RH. All studies on 1-year survival had no obvious heterogeneity $\left(I^{2}=48.3 \%, P\right.$ heterogeneity $\left.=0.102\right)$. No statistically significant heterogeneity was observed for all studies on 3-year and 5-year survival rates $\left(I^{2}=0 \%, P_{\text {het- }}\right.$ erogeneity $=0.519 ; I^{2}=0 \%, P$ heterogeneity $=0.643$, respectively).

Subgroup analysis demonstrated that despite the different publication years and the number of cases of leftside hepatectomy, the results of 1-, 3-, and 5-year survival rate showed no obvious difference. The 1- and 3- year survival rates under the subgroup of different regions were also the same. However, patients who underwent $\mathrm{LH}$ in western centers were associated with poor 5-year survival results (Table 3).

\section{Overall postoperative morbidity and major postoperative} morbidity

Five studies with 590 patients provide information on overall postoperative morbidity, with rates of $50.4 \%$ (132

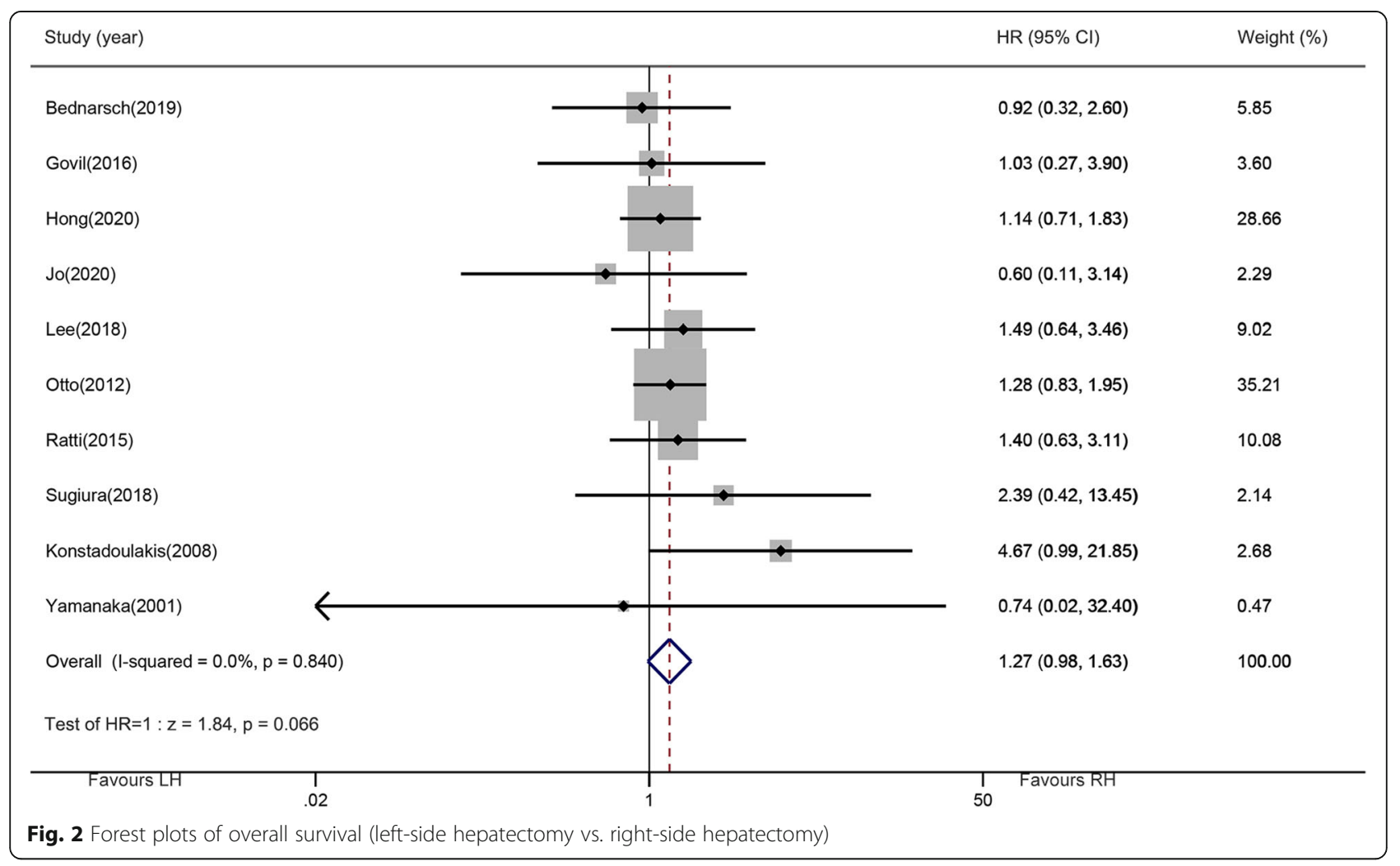




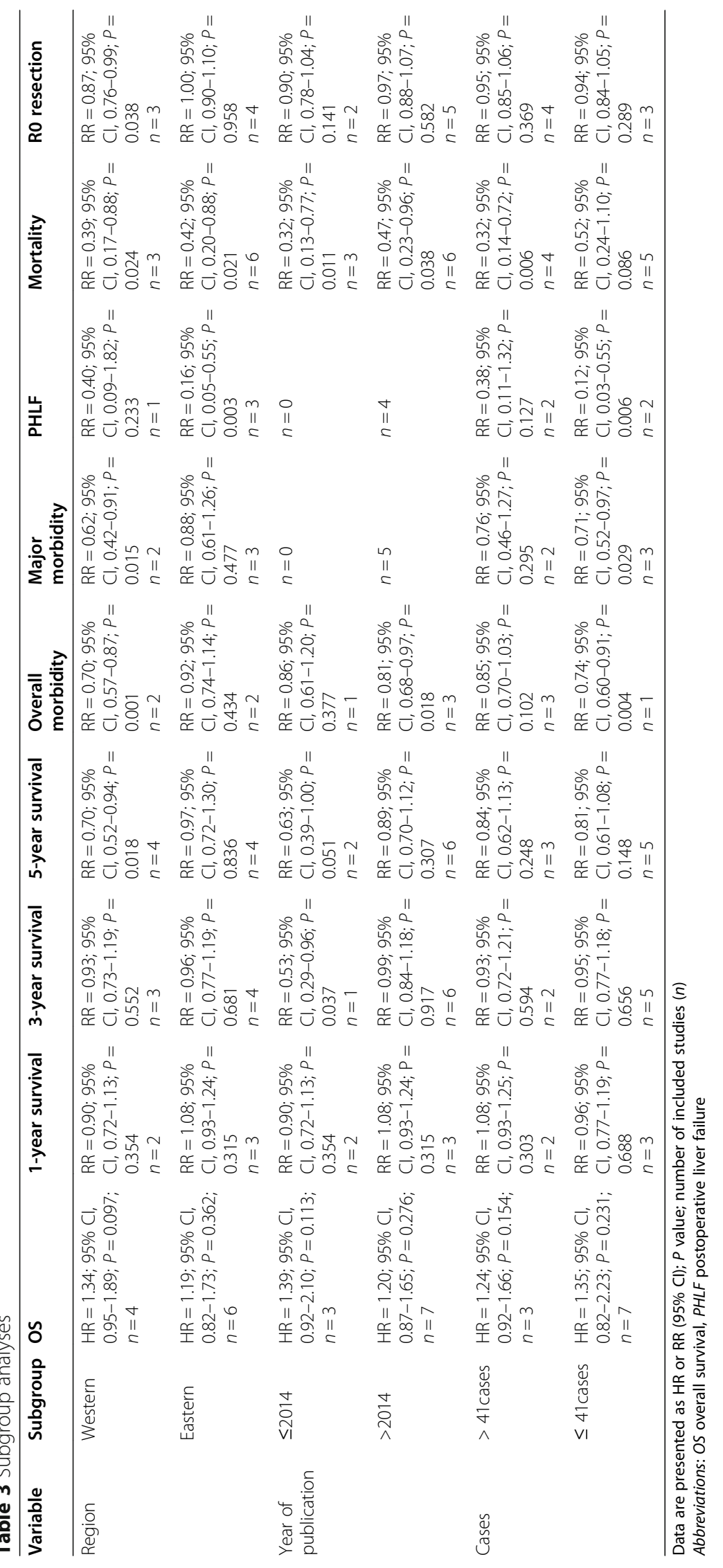




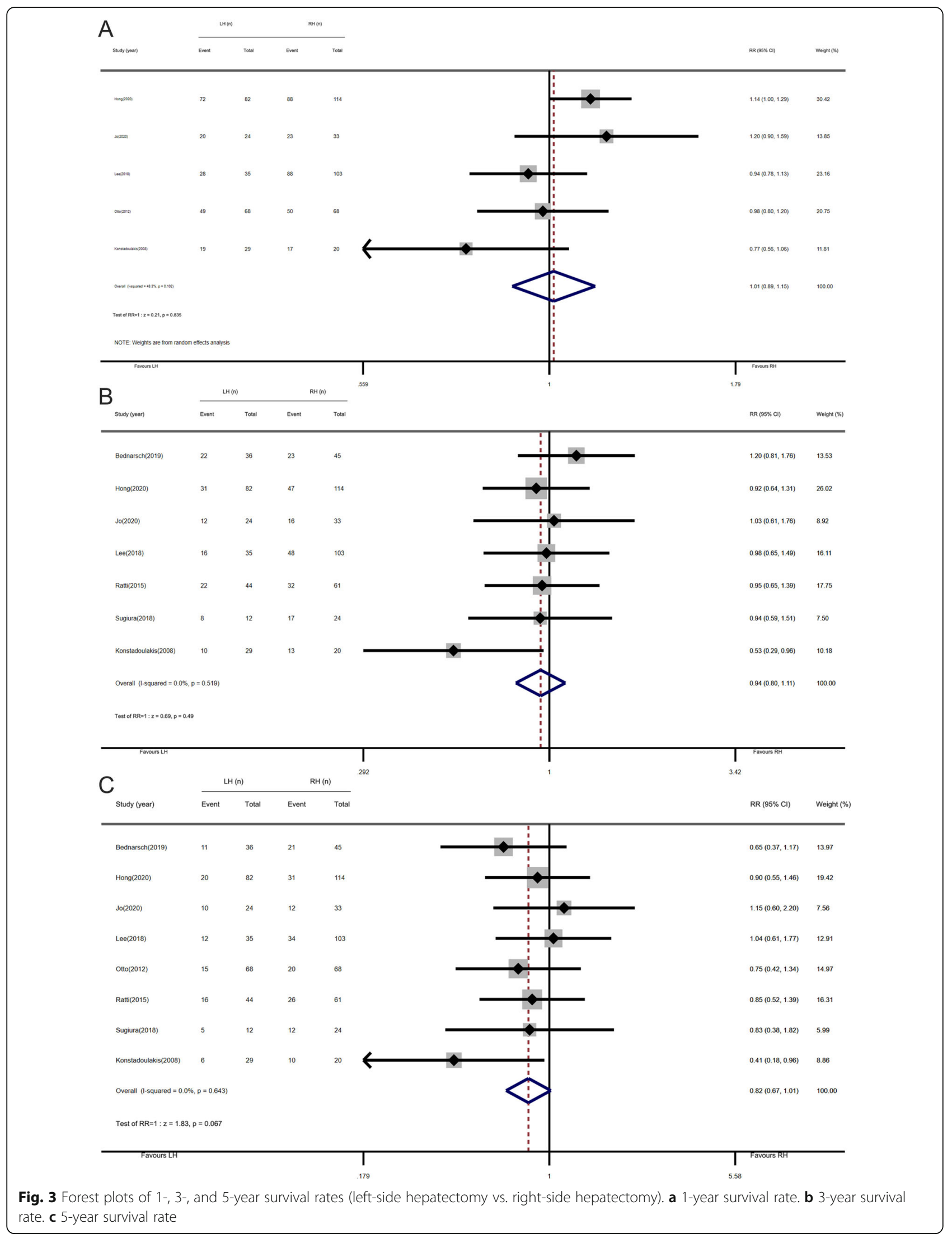


of 262) in the LH group and 61.9\% (203 of 328) in the $\mathrm{RH}$ group. As shown in Fig. 4a, the pooled RR was 0.82 (95\% CI, 0.71-0.96; $P=0.014$ ), and the overall morbidity of the LH group was significantly lower than that of the $\mathrm{RH}$ group. The heterogeneity between the studies was not obvious $\left(I^{2}=13.9 \%, P\right.$ heterogeneity $\left.=0.323\right)$. Major postoperative morbidity was mentioned in five studies with 315 patients; major morbidity occurred in 34.5\% (48 of 139) of patients in the LH group and $45.5 \%$ (80 of $176)$ in the RH group. The pooled RR was 0.73 (95\% CI, $0.56-0.95 ; P=0.020$; Fig. 4b). The results suggested that $\mathrm{RH}$ group had a higher risk of serious postoperative complications, and there was no heterogeneity among the studies $\left(I^{2}=0 \%, P\right.$ heterogeneity $\left.=0.544\right)$.

Subgroup analysis indicated that LH was associated with reduced overall morbidity in post-2014, western center studies and less-experienced centers ( $\leq 41$ cases). However, in eastern center and pre-2014 studies, there was no relationship between the two procedures and overall morbidity. All major morbidity data were collected from the studies published after 2014. The results of the western center studies and less-experienced centers were consistent with the meta-analysis, but no significant differences were observed in the eastern center studies (Table 3).

\section{Post-hepatectomy liver failure and procedure-related mortality}

Four studies reported data about post-hepatectomy liver failure in 373 patients. In the LH and RH group, PHLF rate was $2.5 \%$ (4 of 161) and $12.7 \%$ (27 of 212), respectively. Figure 5 a shows the pooled results of the fixedeffects model; the pooled RR for PHLF was 0.22 (95\% CI, 0.09-0.56; $P=0.002$ ). These results showed that performing LH could reduce the possibility of posthepatectomy liver failure. Nine studies with 976 patients reported perioperative mortality. The mortality rates in the LH group and RH group were 3.9\% (16 of 411) and $8.8 \%$ (47 of 535), respectively. As depicted in the forest plots, the pooled RR was 0.41 (95\% CI, 0.23-0.70; $P=$ 0.001 ), and LH significantly reduces perioperative mortality relative to RH (Fig. 5b). For post-hepatectomy liver failure and postoperative mortality, no heterogeneity was observed between different studies $\left(I^{2}=0 \%, P\right.$ heterogeneity $=0.625 ; I^{2}=0 \%, P$ heterogeneity $=0.954$, respectively).

In the subgroup analysis, the results of the eastern center and less-experienced centers showed that the LH group presented a lower incidence of PHLF. Regarding mortality, regardless of changes in region and publication year, LH was significantly associated with lower mortality. And in centers where LH was performed in more than 41 cases, the mortality rate was lower (Table 3).

\section{R0 resection rate}

A total of 7 studies reported R0 resection rate of 885 HCCA patients. In the LH group, 70.8\% (267 of 377) of patients achieved negative margin, while in the $\mathrm{RH}$ group, the data was $76.2 \%$ (387 of 508). The pooled analysis results showed that the RR of R0 resection rate was 0.95 (95\% CI, 0.87-1.03; $P=0.179$ ) without heterogeneity $\left(I^{2}=0 \%, P_{\text {heterogeneity }}=0.607\right.$; Fig. 6a). No statistical difference in $\mathrm{R} 0$ resection rate between $\mathrm{LH}$ and $\mathrm{RH}$ was identified. Subgroup analysis showed that the results of the western center were inconsistent with the metaanalysis, that is, a higher $\mathrm{R} 0$ resection rate could be obtained by RH (Table 3 ).

\section{Operation time}

Nine studies with a total of 846 patients reported operating time. Based on the fixed-effects model, there was a low level of heterogeneity between the studies $\left(I^{2}=\right.$ $45.1 \%, P$ heterogeneity $=0.078)$. Considering $I^{2}$ as critical at $50 \%$, the random-effects model was used to pool the studies in a more conservative way. As shown in Fig. 6b, the pooled MD was 38.68 (95\% CI, 7.41-69.95; $P=$ $0.015)$, indicating that the operation time in the $\mathrm{LH}$ group was significantly longer than that in the $\mathrm{RH}$ group.

\section{Publication bias}

Figure 7 shows a funnel plot of OS. Neither Begg's test nor Egger's test found significant publication bias, that is, the $P$ values for the outcome was greater than 0.05 . Since the number of studies included in other endpoints in the meta-analysis was small, funnel plots, Begg's test, and Egger's test were not performed to assess publication bias.

\section{Discussion}

The evidence indicated that the effect of palliative treatment for HCCA was limited, and surgery is the only treatment that can improve long-term survival. Bile duct resection combined with major hepatectomy has been regarded as the standard surgical method for HCCA. In order to compare the efficacy and safety of $\mathrm{LH}$ and $\mathrm{RH}$, we performed this meta-analysis. The results of our analysis show that $\mathrm{LH}$ is comparable to $\mathrm{RH}$ in terms of long-term survival. However, comparing with $\mathrm{RH}, \mathrm{LH}$ has reduced overall morbidity, major morbidity, postoperative liver failure, mortality rates, and longer operative time. Furthermore, it has been found that no significant difference existed in the rate of $\mathrm{R} 0$ resection between $\mathrm{LH}$ and $\mathrm{RH}$.

It is common that radical surgery with negative margins is the only effective treatment for HCCA. Therefore, it is significant to identify the opportunities of surgical treatment for HCCA patients. At the same time, 


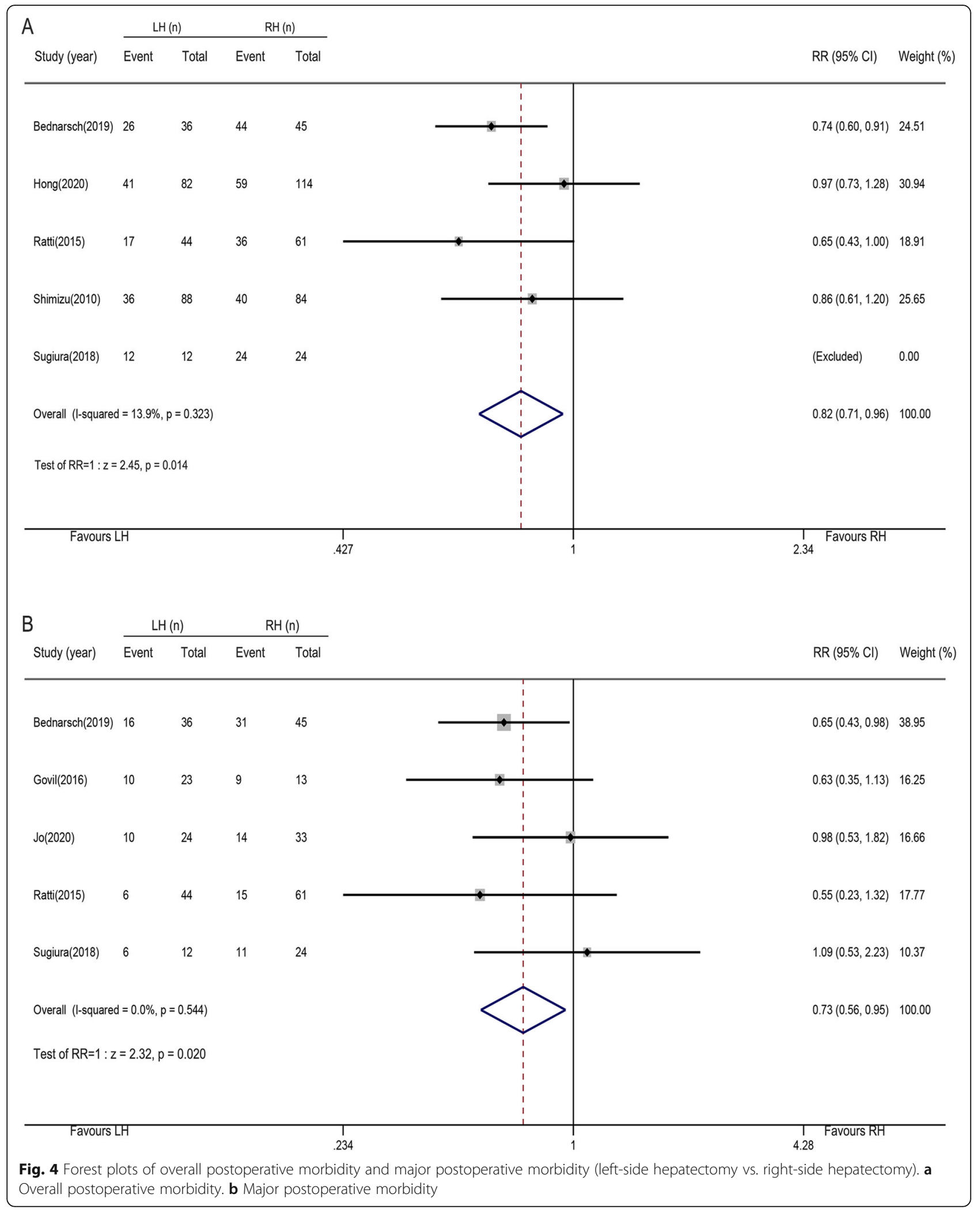




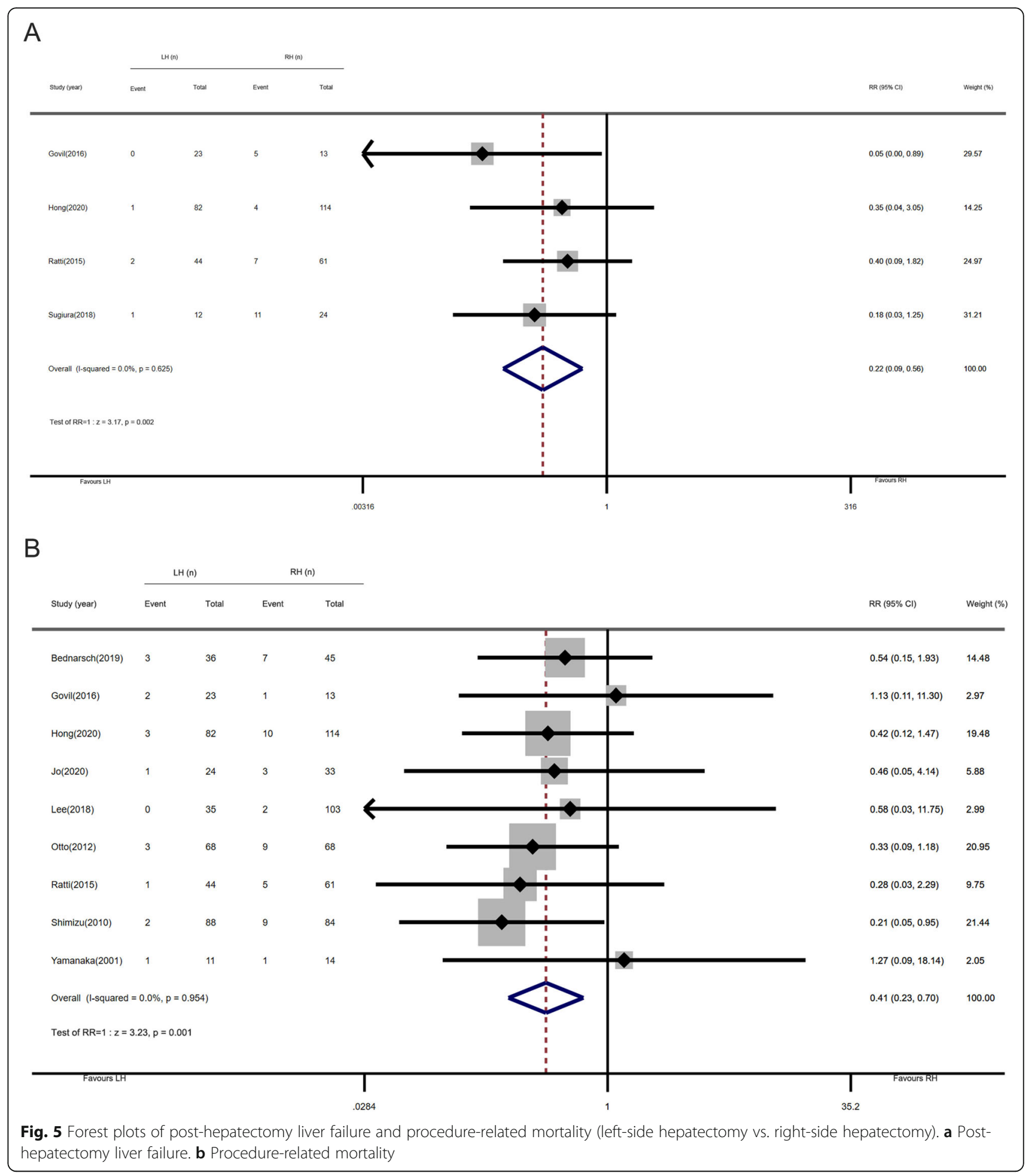

preoperative imaging plays a key role in determining the type of operation. These all require precise preoperative diagnosis, tumor staging, tumor localization, and evaluation of FLR. Preoperative diagnosis methods include abdominal ultrasound, multi-detector-row computed tomography (MDCT), magnetic resonance imaging
(MRI), positron emission tomography/computed tomography (PET/CT), and invasive examinations such as laparoscopy and cholangiography. A number of studies have shown that MDCT is more accurate in evaluating biliary and vascular involvement [36], and a research by Fukami et al. has also proved that multi-slice spiral CT 


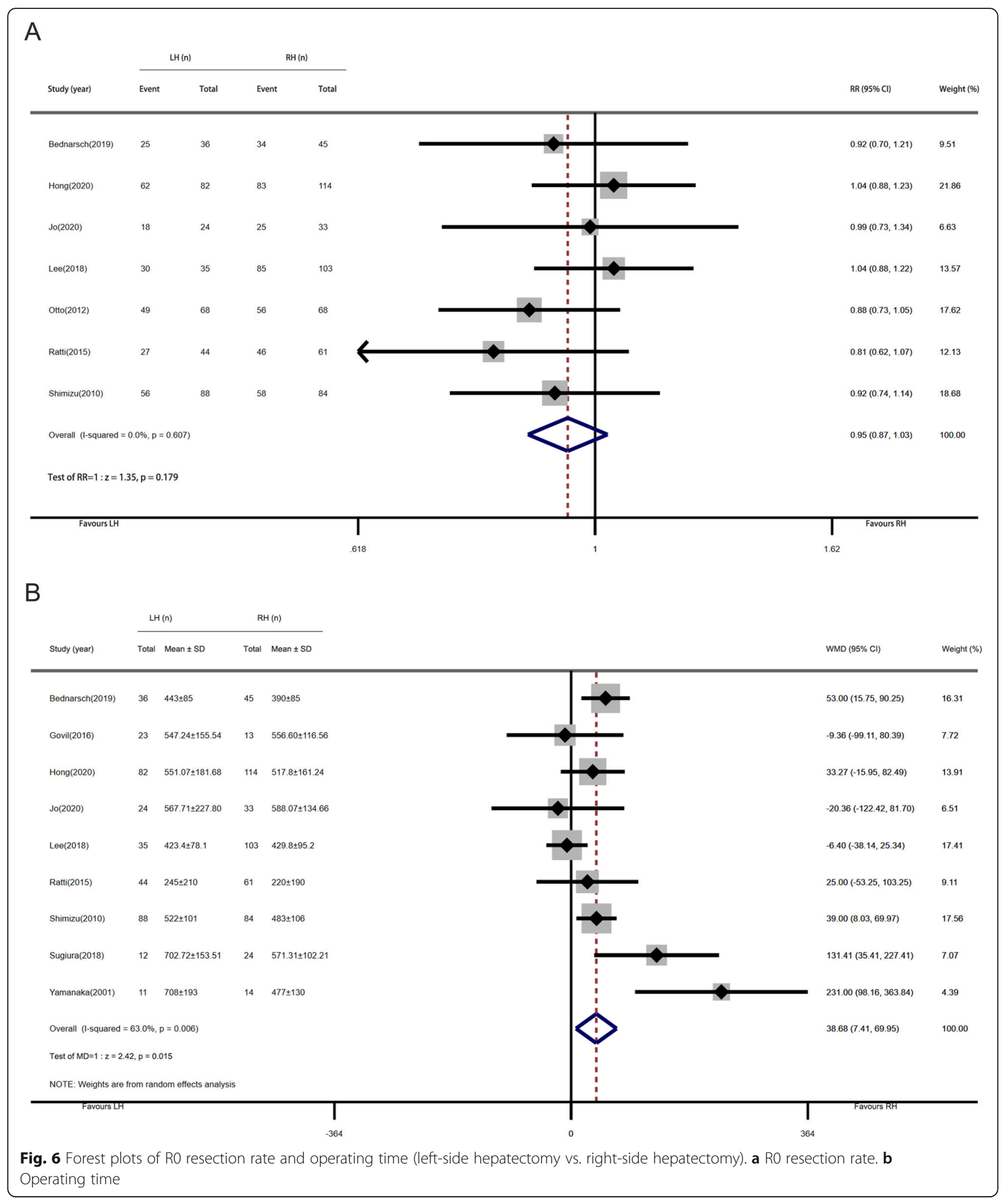

is useful for evaluating right hepatic artery (RHA) invasion of perihilar cholangiocarcinoma [37]. Additionally, this conclusion is of great significance to the formulation of the surgical plan for HCCA that mainly involves the left side and RHA, that is, LH plus RHA resection and reconstruction. MRI is considered to be equivalent to MDCT and can be used as an imaging technique to replace MDCT [38]. Furthermore, MRI as well as MDCT 


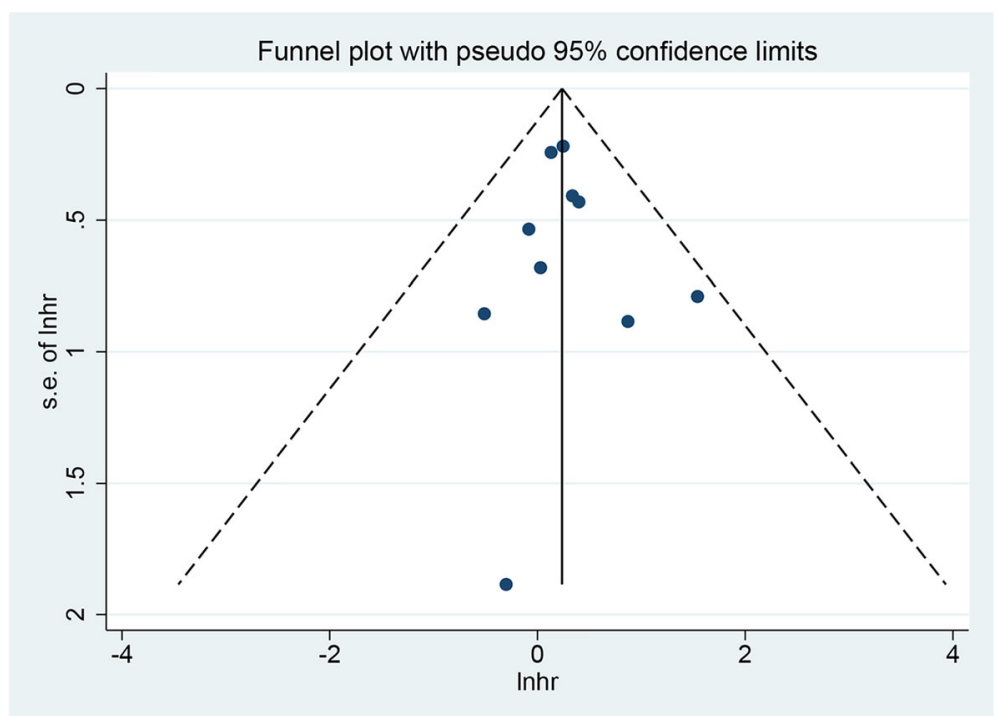

Fig. 7 Funnel plot of overall survival

plays an important role in calculating FLR [39]. As for the judgment of lymph node metastasis, MDCT has limited accuracy $[36,38]$, while PET/CT performs better in judging lymph node metastasis, with a sensitivity of $67.9 \%$ and a specificity of $88.0 \%$. And it performs better in assessing the liver, peritoneum, or other distant metastasis [40]. However, it is difficult for PET/CT to distinguish benign and malignant lesions [41]. In a word, every preoperative imaging method has their own advantages, and for each specific patient, an optimized and individualized preoperative examination strategy should be developed to provide guidance for treatment.

Due to technical limitations and anatomical disadvantages, many surgeons choose RH $[10,12]$. But recently, more centers began to take LH into the HCCA clinical treatment. The present study showed that the long-term survival of LH is not worse than that of RH. Subgroup analysis demonstrated that only the western center group performed better on 5-year survival after RH. The results of the eastern center group, the different publication years, and different cases of LH were analyzed in a meta-analysis. Some authors thought that R0 resection was the most important factor for improving survival after surgical resection [4, 42]. Here, in our metaanalysis including a subgroup analysis, the results were consistent, suggesting that among HCCA patients treated with surgery, R0 resection may be the most important factor for improving survival. The present results provided convincing evidence that there is a positive effect of R0 resection on long-term survival. Therefore, it is reasonable to assume that in addition to tumor location, $\mathrm{R} 0$ resection rate is also a determinant of surgical procedure.
Neuhaus et al. [43] recommended additional caudate lobectomy to increase radicality, while more supporters believed that caudate lobectomy should be performed routinely based on anatomical and histopathological perspectives [44, 45]. Birgin et al. [46] presented a pooled RR value of 1.40 , which was based on the 4 studies, reflecting a higher risk of residual tumors at the resection margin in patients without the caudate lobectomy. In the studies that we included, all the patients have undergone caudate lobe resection, but in some studies, only $80-90 \%$ patients have undergone caudate lobe resection. In view of partial incomplete data and unclear implementation criteria, the subgroup analysis based on caudate lobectomy was regrettably not performed.

In a matched cohort study of Hosokawa et al., the long-term survival, short-term outcomes, and R0 resection of left trisectionectomy (LT) and right hemihepatectomy were comparable [47]. In Esaki et al.'s study, the three groups of left trisectionectomy, left hemihepatectomy, and right hemihepatectomy were compared. The results showed that although the Grade IIIa complications of the LT group were higher than those of the other two groups, the survival of the three groups was comparable. And there was no difference in R0 and overall morbidity between the LT group and right hemihepatectomy group [48]. Natsume et al. focused on the comparison of clinical significance between LT and left hemihepatectomy indicating that the overall morbidity of LT was significantly higher than that of left hemihepatectomy, but the mortality and 5-year survival rates of the two groups were similar [10].

Analysis of morbidity and mortality revealed that LH was associated with better short-term outcomes, with 
both overall and major morbidity, postoperative liver failure, and mortality. A subgroup analysis also confirms this result. Of note, the overall morbidity of the $\mathrm{LH}$ group is only lower in studies published after 2014 and in western centers. As for major morbidity, the LH group performed better than the RH group in the subgroup analysis of region (in the western center). The differences in the eastern and western treatment strategies could be further investigated to provide ideas for further optimization of surgery. It was interesting that the PHLF rate of the eastern center group after performing $\mathrm{LH}$ was significantly reduced which was considered to be related to the active biliary drainage and PVE in the eastern center group [49]. However, there is only one study in the western center group in the subgroup analysis, so the results should be interpreted with cautiously caution. In addition, the date of major morbidity and PHLF were provided by studies published after 2014. It was not clear whether advances in technology and perioperative management in recent years have improved major morbidity and PHLF. When reporting mortality, the criteria for counted days were not uniformed. In theory, 30 days had a reduced mortality rate compared to 90 days, and due to the inconsistent days, it may post misleading influence on our final results. In the subgroup analysis with different numbers of LH cases, in the more experienced centers, the mortality rate of the LH group was lower than that of the RH group, which is also consistent with our conventional understanding. However, for the mortality rate including PHLF, the centers with the number of examples $<41$ cases can obtain better results in the LH group. We consider that these centers have less experience, so they will be more cautious in surgery and have a more detailed surgery management, but the final mortality rate may still be related to experience. Since the number of studies included in the metaanalysis is not sufficient, the understanding of the results needs to be more cautious, and we hope that there will be more related study to be included in the future.

The PHLF caused by insufficient residual liver volume after major hepatectomy is the most fatal complication, with a mortality rate of $52-68 \%$ [50]. Kawasaki et al. [12]. showed that patients with HCCA routinely performed biliary drainage and PVE before extensive hepatectomy, and the hospital mortality rate can be reduced to as low as $1.3 \%$. Preoperative drainage is thought to improve liver function in patients with jaundice, which could reduce PHLF and death. Endoscopic biliary stenting and endoscopic nasobiliary drainage are superior to percutaneous transhepatic biliary drainage because they can reduce the incidence of tumor spread. And given the increase in major morbidity, routine preoperative drainage is not recommended [51]. PVE is believed to increase FLR, but there is no consensus on the indication criteria. In this meta-analysis, various studies conducted biliary drainage and PVE under the premise of different standards, hoping to further clarify the indications of biliary drainage and PVE in the future.

This meta-analysis has some limitations. Firstly, due to the rarity of HCCA, the included studies were all cohort studies, and there are no randomized controlled trials, which would cause selection bias. The quantity of sample is insufficient in some studies, and differences in treatment experience may affect the accuracy of the results. Secondly, there was heterogeneity among the studies on 1-year survival rate and operation time, but the degree was low. Thirdly, the Bismuth classification of tumors in each study is also different, but the data is not sufficient for subgroup analysis based on Bismuth classification. We have taken specific records of every surgery including hemihepatectomy, extended hemihepatectomy, and trisectionectomy. However, samples in most studies were not sufficient to conduct further analysis of surgery because of low incidence of HCCA. It is hoped that further analysis based on different Bismuth classification and treatment modality would be conducted in the future.

In conclusion, the present meta-analysis suggests that for resectable HCCA patients, $\mathrm{LH}$ and RH have comparable survival benefits, $\mathrm{R} 0$ resection rates, and lower morbidity and mortality. LH is safe and feasible. We recommend that the choice of $\mathrm{LH}$ or $\mathrm{RH}$ should be based on the specific anatomy of the tumor to achieve radical cure as much as possible, while optimizing perioperative management to reduce postoperative morbidity and mortality.

To the best of our knowledge, this is the first metaanalysis comparing the outcomes of $\mathrm{LH}$ and $\mathrm{RH}$ to date. Moreover, detailed data about preoperative drainage and PVE were analyzed. We found that although former studies had performed well in comparing $\mathrm{LH}$ and $\mathrm{RH}$ for HCCA, there still remained a number of aspects to be improved, such as Bismuth Clarification, preoperative drainage, preoperative portal vein embolization, and vascular resection. We hope more comprehensive and detailed data about these aspects to be provided in the following researches, and if so, the more convinced results of meta-analysis can be concluded for clinical treatments. And given the low incidence of HCCA, further randomized trials in the real-world may also be needed.

\section{Abbreviations}

HCCA: Hilar cholangiocarcinomaLHLeft-side hepatectomyRHRight-side hepatectomyOSOverall survivalHRHazard ratioRRRelative riskMDMean differenceCIConfidence intervalFLRFuture liver remnantPHLFPostoperative liver failurePVEPortal vein embolizationPRISMAPreferred Reporting Items for Systematic Review and Meta-analysesMOOSEMeta-analysis of Observational Studies in EpidemiologyRCTsRandomized controlled trialsPBDPercutaneous biliary drainageEBDEndoscopic biliary drainageNOSNewcastle-Ottawa quality assessment scaleSDStandard deviation 


\section{Supplementary Information}

The online version contains supplementary material available at https://doi. org/10.1186/s12957-021-02213-6

Additional file 1 Supplementary Table 1. Search strategy.

\section{Acknowledgements}

Not applicable.

\section{Authors' contributions}

JW provided the conception, designed this project, and provided the administrative support. WW and QC conducted the literature research, study selection, and data extractions. WW, QC, JC, DC, and XF drafted this manuscript and contributed in reviewing the manuscript for intellectual content. The authors have read and approved the final manuscript.

\section{Funding}

This work was supported by the National Natural Science Foundation of China (No.81874228) and Grant from Health Commission of Zhejiang Province (JBZX-202004).

\section{Availability of data and materials}

All data are fully available without restriction.

\section{Declarations}

\section{Ethics approval and consent to participate}

All our analyses were based on previous published studies; therefore, no ethical approval and consent to participate are required.

\section{Consent for publication}

All analyses were based on the previous published studies; thus, no consent for publication is required.

\section{Competing interests}

All authors have completed the ICMJE uniform disclosure form. The authors declare that they have no competing interest.

\section{Author details}

${ }^{1}$ Division of Hepatobiliary and Pancreatic Surgery, Department of Surgery, First Affiliated Hospital, Zhejiang University School of Medicine, Hangzhou 310003, Zhejiang Province, China. ${ }^{2}$ Key Laboratory of Combined Multi-organ Transplantation, Ministry of Public Health, First Affiliated Hospital, Zhejiang University School of Medicine, Hangzhou 310003, China. ${ }^{3}$ Key Laboratory of Organ Transplantation, Research Center for Diagnosis and Treatment of Hepatobiliary Diseases, Hangzhou 310003, Zhejiang Province, China.

\section{Received: 30 December 2020 Accepted: 23 March 2021}

\section{Published online: 10 April 2021}

\section{References}

1. Razumilava N, Gores GJ. Cholangiocarcinoma. Lancet. 2014;383(9935):216879. https://doi.org/10.1016/S0140-6736(13)61903-0.

2. Cillo U, Fondevila C, Donadon M, Gringeri E. Surgery for cholangiocarcinoma. Liver Int. 2019;39(Suppl 1):143-55.

3. Bhardwaj N, Garcea G, Dennison AR, Maddern GJ. The surgical management of Klatskin tumours: has anything changed in the last decade? World J Surg. 2015;39(11):2748-56. https://doi.org/10.1007/s00268-015-3125-2.

4. Zhang XF, MHr S, Bagante F, Ethun CG, Salem A. The impact of intraoperative re-resection of a positive bile duct margin on clinical outcomes for hilar cholangiocarcinoma. Ann Surg Oncol. 2018;25(5):1140-9. https://doi.org/10.1245/s10434-018-6382-0

5. Nagino M, Ebata T, Yokoyama Y, Igami T, Sugawara G. Evolution of surgical treatment for perihilar cholangiocarcinoma: a single-center 34-year review of 574 consecutive resections. Ann Surg Oncol. 2013;258(1):129-40.

6. Ito F, Agni R, Rettammel RJ, Been MJ, Cho CS, Mahvi DM, et al. Resection of hilar cholangiocarcinoma: concomitant liver resection decreases hepatic recurrence. Ann Surg. 2008:248(2):273-9. https://doi.org/10.1097/SLA.0b013 e31817f2bfd.
7. Ramos E. Principles of surgical resection in hilar cholangiocarcinoma. World J Gastrointest Oncol. 2013;5(7):139-46. https://doi.org/10.4251/wjgo.v5.i7.13 9.

8. Xiang F, Hu ZM. Chance and challenge of associating liver partition and portal vein ligation for staged hepatectomy. Hepatobiliary Pancreat Dis Int. 2019:18(3):214-22. https://doi.org/10.1016/j.hbpd.2019.04.006.

9. Miyazaki M, Yoshitomi H, Miyakawa S, Uesaka K, Unno M, Endo I, et al. Clinical practice guidelines for the management of biliary tract cancers 2015: the 2nd English edition. J Hepatobiliary Pancreat Sci. 2015;22(4):24973. https://doi.org/10.1002/jhbp.233.

10. Natsume S, Ebata T, Yokoyama Y, Igami T, Sugawara G. Clinical significance of left trisectionectomy for perihilar cholangiocarcinoma: an appraisal and comparison with left hepatectomy. Ann Surg. 2012;255(4):754-62. https:// doi.org/10.1097/SLA.0b013e31824a8d82.

11. Shimizu H, Kimura F, Yoshidome H, Ohtsuka M, Kato A. Aggressive surgical resection for hilar cholangiocarcinoma of the left-side predominance: radicality and safety of left-sided hepatectomy. Ann Surg. 2010;251(2):281-6. https://doi.org/10.1097/SLA.0b013e3181be0085.

12. Kawasaki S, Imamura H, Kobayashi A, Noike T, Miwa S, Miyagawa S. Results of surgical resection for patients with hilar bile duct cancer: application of extended hepatectomy after biliary drainage and hemihepatic portal vein embolization. Ann Surg. 2003;238(1):84-92. https://doi.org/10.1097/01.SLA. 0000074984.83031 .02

13. Uesaka K. Left hepatectomy or left trisectionectomy with resection of the caudate lobe and extrahepatic bile duct for hilar cholangiocarcinoma (with video). J Hepatobiliary Pancreat Sci. 2012;19(3):195-202. https://doi.org/10.1 007/s00534-011-0474-6.

14. Farges $\mathrm{O}$, Regimbeau JM, Fuks D, le Treut YP, Cherqui $D$, Bachellier $P$, et al. Multicentre European study of preoperative biliary drainage for hilar cholangiocarcinoma. Br J Surg. 2013;100(2):274-83. https://doi.org/10.1002/ bjs.8950.

15. Jo H-S, Kim D-S, Yu Y-D, Kang W-H, Yoon KC. Right-side versus left-side hepatectomy for the treatment of hilar cholangiocarcinoma: a comparative study. World J Surg Oncol. 2020;18(1):3-3. https://doi.org/10.1186/s12957-01 9-1779-1.

16. Yasuda $Y$, Larsen $P N$, Ishibashi T, Yamashita $K$, Toei $H$. Resection of hilar cholangiocarcinoma with left hepatectomy after pre-operative embolization of the proper hepatic artery. HPB (Oxford). 2010;12(2):147-52. https://doi. org/10.1111/j.1477-2574.2009.00152.x.

17. Hosokawa I, Shimizu H, Yoshidome H, Ohtsuka M, Kato A. Surgical strategy for hilar cholangiocarcinoma of the left-side predominance: current role of left trisectionectomy. Ann Surg. 2014;259(6):1178-85.

18. Nagino M. Perihilar cholangiocarcinoma: a surgeon's viewpoint on current topics. J Gastroenterol. 2012;47(11):1165-76. https://doi.org/10.1007/s00535012-0628-6.

19. Govil S, Bharatan A, Rammohan A, Kanagavelu R, Kaliamoorthy I, Reddy MS, et al. Liver resection for perihilar cholangiocarcinoma - why left is sometimes right. HPB (Oxford). 2016;18(7):575-9. https://doi.org/10.1016/j. hpb.2016.05.002.

20. Moher D, Liberati A, Tetzlaff J, Altman DG. Preferred Reporting Items for Systematic Reviews and Meta-Analyses: the PRISMA statement. An Intern Med. 2009;151(4):264-9. https://doi.org/10.7326/0003-4819-151-4-2009081 80-00135.

21. Stroup DF, Berlin JA, Morton SC, Olkin I, Williamson GD, Rennie D. Metaanalysis of Observational Studies in Epidemiology. JAMA. 2000;283(15):200812. https://doi.org/10.1001/jama.283.15.2008.

22. Parmar MK, Torri $V$, Stewart L. Extracting summary statistics to perform meta-analyses of the published literature for survival endpoints. Stat Med. 1998;17(24):2815-34. https://doi.org/10.1002/(SICI)1097-0258(19981230)17:24 $<2815:: A I D-S I M 110>3.0 . C O ; 2-8$

23. Tierney JF, Stewart LA, Ghersi D, Burdett S, Sydes MR. Practical methods for incorporating summary time-to-event data into meta-analysis. Trials. 2007; 8(1):16. https://doi.org/10.1186/1745-6215-8-16

24. Wells GA, Shea BJ, O'Connell D, Smitch M. The Newcastle-Ottawa scale (NOS) for assessing the quality of non-randomized studies in meta-analysis. Appl Eng Agric. 2014;18:727-34.

25. Luo D, Wan X, Liu J, Smitch M, Hirata K. Optimally estimating the sample mean from the sample size, median, mid-range and/or mid-quartile. Stat Methods Med Res. 2016;0(0):1-21

26. Wan X, Wang W, Liu J, Tong AK. Estimating the sample mean and standard deviation from the sample size, median, range and/or interquartile range. 
BMC Med Res Methodol. 2014;14(1):135. https://doi.org/10.1186/1471-22 88-14-135.

27. Higgins JP, Thompson SG, Deeks JJ, Smitch M. Measuring inconsistency in meta-analyses. Br Med J. 2003;327(7414):557-60. https://doi.org/10.1136/ bmj.327.7414.557.

28. Bednarsch J, Czigany Z, Lurje I, et al. Left- versus right-sided hepatectomy with hilar en-bloc resection in perihilar cholangiocarcinoma. HPB (Oxford). 2019;22(3):437-44.

29. Hong SS, Han DH, Choi GH, Choi JS. Comparison study for surgical outcomes of right versus left side hemihepatectomy to treat hilar cholangiocellular carcinoma. Ann Surg Treat Res. 2020;98(1):15-22. https:// doi.org/10.4174/astr.2020.98.1.15.

30. Lee Y, Choi D, Han S, Han IW, Heo JS, Choi SH. Comparison analysis of leftside versus right-side resection in Bismuth type III hilar cholangiocarcinoma. Ann Hepatobiliary Pancreat Surg. 2018;22(4):350-8. https://doi.org/10.14 701/ahbps.2018.22.4.350

31. Otto G, Heise M, Hoppe-Lotichius M, Pitton M, Hansen T. Hilar cholangiocarcinoma: right versus left hepatectomy. Zentralbl Chir. 2012; 137(6):535-40. https://doi.org/10.1055/s-0032-1328024.

32. Ratti F, Cipriani F, Piozzi G, Catena M, Paganelli M, Aldrighetti L. Comparative analysis of left- versus right-sided resection in Klatskin tumor surgery: can lesion side be considered a prognostic factor? I Gastrointest Surg. 2015;19(7):1324-33. https://doi.org/10.1007/s11605-015-2840-1.

33. Sugiura T, Okamura Y, Ito T, Yamamoto Y, Ashida R, Ohgi K, et al. Left Hepatectomy with combined resection and reconstruction of right hepatic artery for Bismuth type I and II perihilar cholangiocarcinoma. World J Surg. 2019;43(3):894-901. https://doi.org/10.1007/s00268-018-4833-1.

34. Konstadoulakis MM, Roayaie S, Gomatos IP, Labow D, Fiel Ml, Miller CM, et al. Aggressive surgical resection for hilar cholangiocarcinoma: is it justified? Audit of a single center's experience. Am J Surg. 2008;196(2):1609. https://doi.org/10.1016/j.amjsurg.2007.07.033.

35. Yamanaka N, Yasui C, Yamanaka J, Ando T, Kuroda N, Maeda S, et al. Left hemihepatectomy with microsurgical reconstruction of the right-sided hepatic vasculature. A strategy for preserving hepatic function in patients with proximal bile duct cancer. Langenbecks Arch Surg. 2001;386(5):364-8. https://doi.org/10.1007/s004230100225.

36. Engelbrecht MR, Katz SS, van Gulik TM, Lameris JS, van Delden OM. Imaging of perihilar cholangiocarcinoma. AJR Am J Roentgenol. 2015;204(4):782-91. https://doi.org/10.2214/AJR.14.12830.

37. Fukami Y, Ebata T, Yokoyama Y, Igami T, Sugawara G, Takahashi Y, et al. Diagnostic ability of MDCT to assess right hepatic artery invasion by perihilar cholangiocarcinoma with left-sided predominance. J Hepatobiliary Pancreat Sci. 2012;19(2):179-86. https://doi.org/10.1007/s00534-011-0413-6.

38. Zhang H, Zhu J, Ke F, et al. Radiological imaging for assessing the respectability of hilar cholangiocarcinoma: a systematic review and metaanalysis. Biomed Res Int. 2015;2015:497942.

39. Wiggers JK, Koerkamp GB, Cieslak KP, Doussot A, Klaveren DV, Allen PJ Postoperative mortality after liver resection for perihilar cholangiocarcinoma: development of a risk score and importance of biliary drainage of the future liver remnant. J Am Coll Surg. 2016;223(2):321-31. https://doi.org/10.1 016/j.jamcollsurg.2016.03.035

40. Li X, Zhang Y, Zhang Y. (18)F-FDG PET/CT may be a suitable method for preoperative diagnosis and evaluation of Chinese older patients with hilar cholangiocarcinoma. BMC Geriatr. 2018;18(1):150.

41. Ruys AT, Bennink RJ, van Westreenen HL, Engelbrecht MR, Busch OR, Gouma DJ, et al. FDG-positron emission tomography/computed tomography and standardized uptake value in the primary diagnosis and staging of hilar cholangiocarcinoma. HPB (Oxford). 2011;13(4):256-62. https://doi.org/10.1111/j.1477-2574.2010.00280.x.

42. Moris D, Kostakis ID, Machairas N, Prodromidou A, Tsilimigras DI, Ravindra $\mathrm{KV}$. Comparison between liver transplantation and resection for hilar cholangiocarcinoma: a systematic review and meta-analysis. Plos One. 2019; 14(7):e0220527.

43. Neuhaus P, Thelen A, Jonas S, Puhl G, Denecke T. Oncological superiority of hilar en bloc resection for the treatment of hilar cholangiocarcinoma. Ann Surg Oncol. 2012;19(5):1602-8. https://doi.org/10.1245/s10434-011-2077-5.

44. Xiang S, Lau WY, Chen XP. Hilar cholangiocarcinoma: controversies on the extent of surgical resection aiming at cure. Int J Colorectal Dis. 2015;30(2): 159-71. https://doi.org/10.1007/s00384-014-2063-z.
45. Kambakamba P, DeOliveira ML. Perihilar cholangiocarcinoma: paradigms of surgical management. Am J Surg. 2014;208(4):563-70. https://doi.org/10.101 6/j.amjsurg.2014.05.017.

46. Birgin E, Rasbach E, Reissfelder C, Rahbari NN. A systematic review and meta-analysis of caudate lobectomy for treatment of hilar cholangiocarcinoma. Eur J Surg Oncol. 2020;46(5):747-53. https://doi.org/1 0.1016/j.ejso.2020.01.023

47. Hosokawa I, Shimizu H, Yoshitomi H, Furukawa K, Takayashiki T. Outcomes of left trisectionectomy and right hepatectomy for perihilar cholangiocarcinoma. HPB. 2019;21:489-98.

48. Esaki M, Shimada K, Nara S, Kishi Y, Sakamoto Y, Kosuge T, et al. Left hepatic trisectionectomy for advanced perihilar cholangiocarcinoma. Br J Surg. 2013 100(6):801-7. https://doi.org/10.1002/bjs.9099.

49. Franken LC, Schreuder AM, Roos E, et al. Morbidity and mortality after major liver resection in patients with perihilar cholangiocarcinoma: a systematic review and meta-analysis. Surgery. 2019;165(5):918-28. https://doi.org/10.101 6/j.surg.2019.01.010

50. Olthof PB, Wiggers JK, Groot KB, Coelen RJ, Allen PJ, Besselink MG. Postoperative liver failure risk score: identifying patients with resectable perihilar cholangiocarcinoma who can benefit from portal vein embolization. J Am Coll Surg. 2017;225(3):387-94. https://doi.org/10.1016/j.ja mcollsurg.2017.06.007.

51. Mehrabi A, Khajeh E, Ghamarnejad O, et al. Meta-analysis of the efficacy of preoperative biliary drainage in patients undergoing liver resection for perihilar cholangiocarcinoma. Eur J Radiol. 2020;125:108897.

\section{Publisher's Note}

Springer Nature remains neutral with regard to jurisdictional claims in published maps and institutional affiliations.
Ready to submit your research? Choose BMC and benefit from:

- fast, convenient online submission

- thorough peer review by experienced researchers in your field

- rapid publication on acceptance

- support for research data, including large and complex data types

- gold Open Access which fosters wider collaboration and increased citations

- maximum visibility for your research: over $100 \mathrm{M}$ website views per year

At BMC, research is always in progress.

Learn more biomedcentral.com/submissions 